\title{
Midbrain-Derived Neurotrophins Support Survival of Immature Striatal Projection Neurons
}

\author{
Maryna Baydyuk, ${ }^{1}$ Yuxiang Xie, ${ }^{1}$ Lino Tessarollo, ${ }^{2}$ and Baoji Xu ${ }^{1}$ \\ ${ }^{1}$ Department of Pharmacology and Physiology, Georgetown University Medical Center, Washington, DC 20057, and ${ }^{2}$ Neural Development Section, Center \\ for Cancer Research, National Cancer Institute, Frederick, Maryland 21702
}

Neuronal death occurs at several stages during embryogenesis and early postnatal development; however, it is unknown how the survival of immature neurons at their origin is regulated before these cells migrate to their final destination. Striatal projection neurons, known as medium-sized spiny neurons (MSNs), in both the direct and indirect pathways are generated in the lateral ganglionic eminence (LGE). Here we report that brain-derived neurotrophic factor and neurotrophin-3 are anterogradely transported from midbrain dopaminergic neurons and support the survival of immature MSNs of the indirect and direct pathways, respectively, in the developing mouse striatum and LGE. These results reveal a novel mode of neurotrophic action in the nervous system by linking neurotrophins to the survival of immature neurons at their origin, while also suggesting that innervating neurons may control the size of their targeting neuronal population in the brain.

\section{Introduction}

There are two crucial factors that determine neuronal population size: proliferation of neural progenitor cells and subsequent death of some newborn neurons. It has been well documented that in the peripheral nervous system (PNS), developing neurons at their final location have to compete for a limited amount of neurotrophic factors produced by their target tissues; neurons unable to obtain sufficient amounts of trophic factors die via programmed cell death (Zweifel et al., 2005). In this way, a peripheral target controls the final size of the innervating neuronal population through neurotrophic factors. Neurotrophins are an important family of neurotrophic factors and include nerve growth factor (NGF), brain-derived neurotrophic factor (BDNF), neurotrophin-3 (NT3), and neurotrophin-4/5 (NT4/5). They exert many biological effects by binding and activating specific Trk receptor tyrosine kinases; NGF activates TrkA, BDNF and NT4/5 activate TrkB, and NT3 activates TrkC (Reichardt, 2006).

Neurons in the CNS originate from the ventricular zone and subventricular zone (VZ/SVZ) and then migrate to their final destinations (Kriegstein and Noctor, 2004). Although ablation of neurotrophic signaling increases programmed cell death in the hippocampal dentate gyrus and cerebellar granular layer during the first two postnatal weeks (Minichiello and Klein, 1996; Alcántara et al., 1997), it remains unclear whether developing CNS neurons that are at their final position are dependent on

Received Aug. 1, 2012; revised Dec. 7, 2012; accepted Dec. 23, 2012.

Author contributions: M.B., Y.X., and B.X. designed research; M.B. and Y.X. performed research; L.T. contributed unpublished reagents/analytic tools; M.B., Y.X., and B.X. analyzed data; M.B. and B.X. wrote the paper.

This work was supported by a grant from the US National Institutes of Health to B.X. (R01 NS050596). We thank Nicole Calakos for Drd1a-tdTomato mice, Stefano Vicini for Drd2-EGFP mice, and Eric Huang for Th-Cre mice.

Correspondence should be addressed to Dr. Baoji Xu, Department of Pharmacology and Physiology, Georgetown University Medical Center, 3900 Reservoir Road NW, Washington, DC 20057. E-mail: bx3@georgetown.edu.

DOI:10.1523/JNEUROSCI.3687-12.2013

Copyright $\odot 2013$ the authors $\quad 0270-6474 / 13 / 333363-07 \$ 15.00 / 0$ target-derived neurotrophic factors for survival, as are developing PNS neurons. Some immature neurons die before they migrate out of the VZ/SVZ (Oppenheim, 1991); however, it also remains to be determined whether immature neurons at their origin need trophic support for survival and, if so, what is the source of neurotrophic factors.

The striatum is a major part of the basal ganglia involved in the control of movement. Approximately 95\% of striatal neurons are medium-sized spiny neurons (MSNs) that are equally divided between two populations (Kawaguchi, 1997). One population expresses Dla dopamine receptor (DRDla) and participates in the initiation of movement via direct projection to the output nuclei of the basal ganglia. The other population expresses D2 dopamine receptor (DRD2) and controls movement inhibition via the indirect pathway (Bolam et al., 2000). In a previous study, we found that TrkB was essential for survival of immature MSNs of the indirect pathway in their birthplace, the lateral ganglionic eminence (LGE), before they migrated to the striatum (Baydyuk et al., 2011). Because TrkB can be activated through a neurotrophin-independent manner (Lee and Chao, 2001), it remains unknown whether these immature MSNs need neurotrophins for survival and, if so, where neurotrophic support comes from. It also is unknown which trophic factor supports the survival of immature MSNs of the direct pathway in the LGE. In the present study, we investigated the identity and the source of neurotrophins that are required for the survival of immature MSNs of both pathways.

\section{Materials and Methods}

Animals. We obtained the following mouse strains from the Jackson Laboratory: $B d n f^{d o x}$ (stock number 4339), $N t f 3^{l o x}$ (stock number 3541) and Wnt1-Cre (stock number 3829). The TrkC-null allele, the Drd1atdTomato strain, the Drd2-EGFP strain, and the Th-Cre strain were previously described (Liebl et al., 1997; Lindeberg et al., 2004; Baydyuk et al., 2011). We generated $B d n f^{\text {fac } Z /+}$ mice by crossing the $B d n f$ lox strain 
generated by Kevin Jones and colleagues (Gorski et al., 2003) to mice expressing Cre recombinase in male germline cells. We used Bdnf LacZ/Lac $Z$ as $B d n f^{-1-}$ mice. Both genders of mice were used. The Georgetown University Animal Care and Use Committee approved all animal procedures used in this study.

Histology. Mice at postnatal day 10 (P10) or older ages were transcardially perfused with PBS and 4\% paraformaldehyde. We did not perfuse newborn mice. Brains were removed from the skull, fixed in $4 \%$ paraformaldehyde overnight, transferred to $30 \%$ sucrose solution for 3-5 d, and sectioned at $50 \mu \mathrm{m}$. Immunohistochemistry was performed as described previously (Baydyuk et al., 2011). Sources and dilution of primary antibodies were as follows: EGFP (Abcam, 1:1000; Clontech Laboratories, 1:10,000), DRD1a (Millipore Bioscience Research Reagents, 1:1000), $\beta$-galactosidase (Promega, 1:300; Cappel, 1:2000), NeuN (Millipore Bioscience Research Reagents, 1:500), DARPP-32 (Cell Signaling Technology, 1:200), calbindin (Sigma, 1:400), TuJ-1 (Covance, 1:2000), and activated caspase-3 (Cell Signaling Technology, 1:200). Secondary antibodies were obtained from the Jackson ImmunoResearch Laboratories and used according to the manufacturer's instruction. X-gal staining was performed as described previously (Xu et al., 2003).

Stereology. We used Stereo Investigator software (MicroBrightField) to count striatal neurons as described previously (Baydyuk et al., 2011). The nucleus accumbens was excluded from the calculation. Measurements were performed on every sixth Nissl-stained coronal sections, extending from the most rostral to the most caudal parts of the striatum $(8-10$ histological sections per brain).

ELISA. BDNF and NT3 Emax ImmunoAssay Systems (Promega) were used to measure BDNF and NT3 protein levels in lysates prepared from the striatum at P21 and embryonic day 16.5 (E16.5).

In situ hybridization. To generate antisense riboprobes, mouse cDNA sequences for Bdnf (GenBank accession number NM_010076, nucleotides 896-1337) and Ntf3 (GenBank accession number NM_008742, nucleotides 214-990) were amplified by PCR and cloned into the pBluscript II KS (-) plasmid (Stratagene). Radioactive in situ hybridization was performed as described previously (Xu et al., 2003).

Rotarod test. We performed the rotarod test as described previously (Xie et al., 2010). The test was performed for three consecutive days, three trials each day with $1 \mathrm{~h}$ between trials. The time mice stayed on the rotating rod was recorded (a maximum time of $300 \mathrm{~s}$ ).

Statistical analysis. All data are expressed as mean \pm SEM. Data were analyzed using Student's $t$ test.

\section{Results \\ BDNF is required for survival of immature MSNs in the indirect pathway}

We first sought to determine whether a neurotrophin acts on the TrkB receptor to support immature MSNs for survival. Because of widespread expression of BDNF in the brain (Hofer et al., 1990), we hypothesized that BDNF may be important for this process. Using ELISA, we found that BDNF was present in lysates prepared from the developing striatum (including the LGE) at E16.5 and the striatum at P21 (Fig. 1A). We then counted striatal neurons in $B d n f^{-1-}$-null mice and wild-type (WT) littermates at $\mathrm{P} 10-\mathrm{P} 14$ and found a $40 \%$ reduction in neuronal number in the striatum of $B d n f^{-1-}$ mice (Fig. $1 B$ ). This neuronal loss profoundly affected MSNs of the indirect pathway, as we found that $52 \%$ of DRD2-expressing MSNs, which were marked by EGFP derived from the Drd2-EGFP transgene (Day et al., 2006), were lost in $B d n f^{-1-}$ mice (Fig. $1 C$ ). These phenotypes are similar to what we observed in mice where the $\operatorname{Trk} B$ gene was deleted in the precursor cells of MSNs (Baydyuk et al., 2011).

To determine whether the loss of striatal neurons in $B d n f^{-/-}$ mice is the result of increased cell death, we used immunohistochemistry of activated caspase- 3 to detect apoptotic cells. In newborn WT mice, the density of apoptotic cells was sevenfold higher in the LGE VZ/SVZ than in the striatum (Fig. 1D,E), suggesting that programmed cell death of MSNs occurs mainly at the site of their origin. In newborn $B d n f^{-/-}$mice, the density of apoptotic cells in both the LGE and the striatum was drastically increased (Fig. 1D,E), indicating the importance of BDNF in survival of MSNs at both their origin and their final position.

To further characterize the identity of cells undergoing apoptosis in the LGE VZ/SVZ and the striatum, we performed double immunofluorescence labeling using antibodies to activated caspase- 3 and specific neuronal markers for different developmental stages. We found that the majority of caspase-3-positive cells in the VZ/SVZ and the striatum at $\mathrm{P} 0$ expressed $\beta$ III-tubulin TuJ-1, an early marker for immature and differentiating neurons (Lee et al., 1990) [74\% (31/42) and 58\% (19/33), respectively; Fig. $1 F]$. These dying cells were also positive for NeuN, a marker for both immature and mature neurons $[81 \%(30 / 37)$ in the VZ/SVZ and $81 \%(13 / 16)$ in the striatum; Fig. $1 F]$. Furthermore, we found that apoptotic cells expressed a marker for immature MSNs, calbindin [82\% (18/22) in the VZ/SVZ and 57\% (13/23) in the striatum; Fig. $1 F]$. However, these apoptotic neurons did not show immunoreactivity to DARPP-32, a terminal differentiation marker of MSNs $(0 / 37$ in the VZ/SVZ and $0 / 17$ in the striatum, Fig. $1 F)$.

Together, these results indicate that BDNF serves as the main ligand for the TrkB receptor to promote survival of immature MSNs in the indirect pathway. A previous observation that the striatum has a normal number of neurons in a $B d n f$ conditional knock-out is likely a result of incomplete $B d n f$ deletion in the embryonic brain (Rauskolb et al., 2010).

\section{Striatal BDNF is derived from dopaminergic neurons of the midbrain}

To identify the source of BDNF that is critical for survival of immature MSNs, we examined the expression of the $B d n f$ gene in the developing brain using a $B d n f^{L a c Z I+}$ knockin mouse strain, in which $\beta$-galactosidase, a product of the LacZ gene, marks cells that normally express BDNF. In adult mice, striatal BDNF protein is synthesized in and anterogradely transported from cell bodies located in the cerebral cortex, substantia nigra, and thalamus (Altar et al., 1997). Consistent with a previous report (Gorski et al., 2003), we observed high levels of BDNF expression in the cerebral cortex and substantia nigra, but not in the striatum, at P21 (Fig. 2A,B). However, we found very little BDNF expression in the cerebral cortex, LGE, and striatum at P0 (Fig. 2C) and E16.5 (Fig. 2E), but did detect BDNF expression in the substantia nigra at P0 (Fig. 2D, arrow) and E16.5 (Fig. 2E, arrow). Moreover, BDNF expression was found in cells expressing tyrosine hydroxylase $(\mathrm{TH})$, a marker for dopaminergic neurons, in the substantia nigra at E16.5 (Fig. 2F).

Since it has been shown that nigrostriatal projections are formed by E16.5 (Voorn et al., 1988), we hypothesized that BDNF is anterogradely transported from midbrain dopaminergic neurons and released in the LGE to promote survival of immature MSNs. To test this hypothesis, we selectively deleted the $B d n f$ gene in dopaminergic neurons by crossing mice containing a floxed $B d n f$ allele $\left(B d n f^{\text {fox }}\right)$ to mice where the IRES-Cre sequence was knocked in at the $3^{\prime}$ untranslated region of the gene for $\mathrm{TH}$ (Th-Cre) (Lindeberg et al., 2004) to produce Bdnfox/lox (control) and Th-Cre;Bdnf fox/lox (mutant; termed $B d n f^{T h}$ ). In situ hybridization confirmed abolishment of BDNF expression in the substantia nigra of $B d n f^{T h}$ mice (Fig. 2G). $B d n f^{T h}$ mice had a phenotype nearly identical to that observed in $B d n f^{-{ }^{-}}$mice, which includes a reduction in striatal neuronal counts at $\mathrm{P} 0$ and P21 by $38 \%$ and $33 \%$, respectively (Fig. $2 H$ ) and an increased density of apoptotic cells in the LGE VZ/SVZ and striatum at P0 (Fig. 2I,J), when compared with control mice. We also observed 

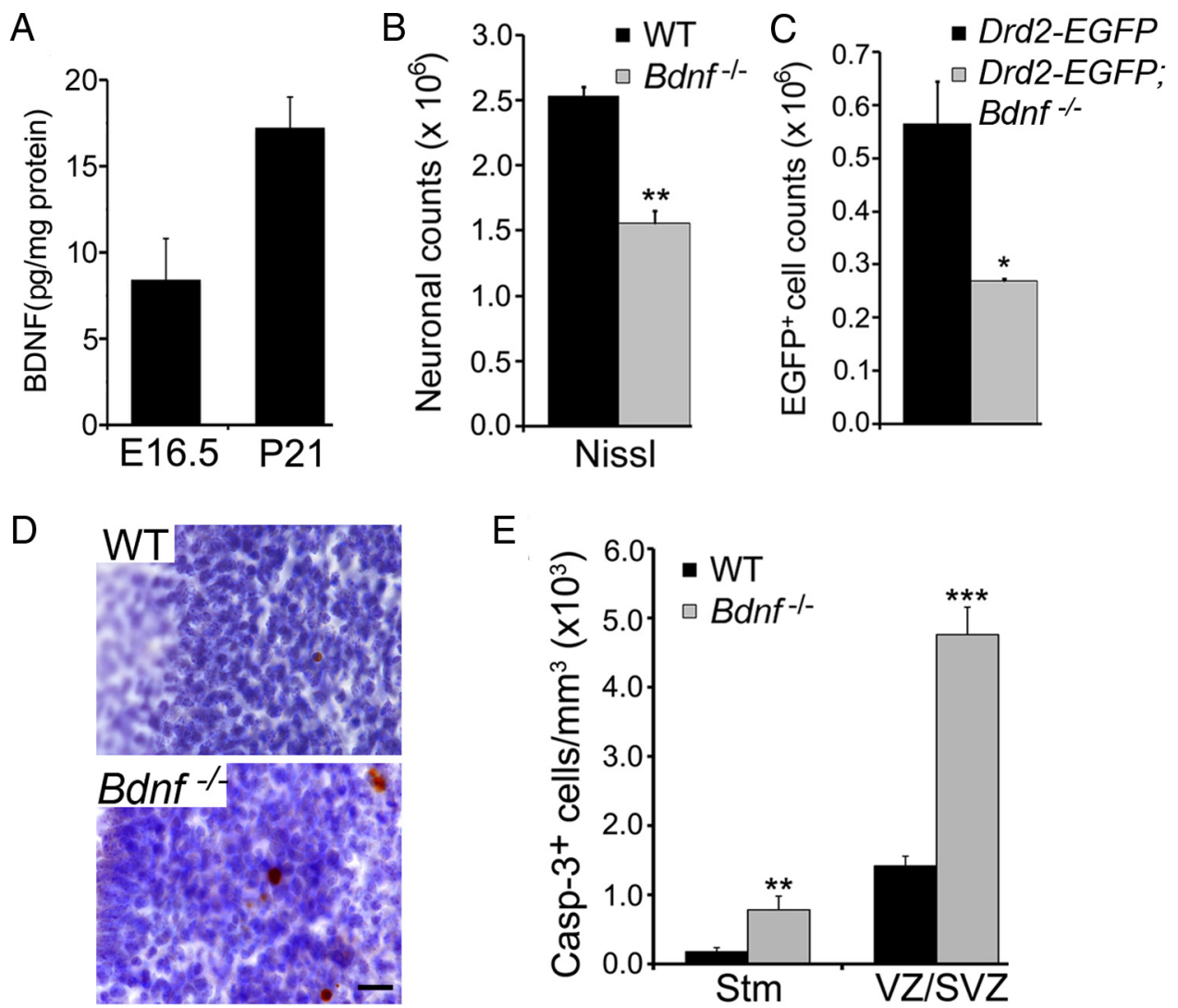

$\mathrm{F}$
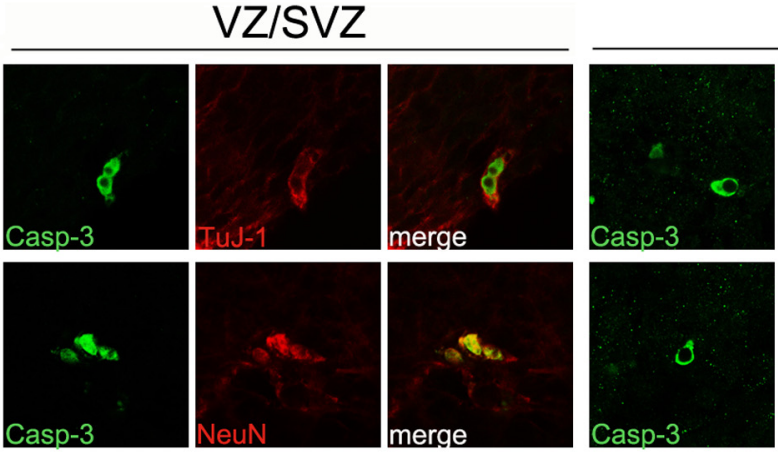

Striatum
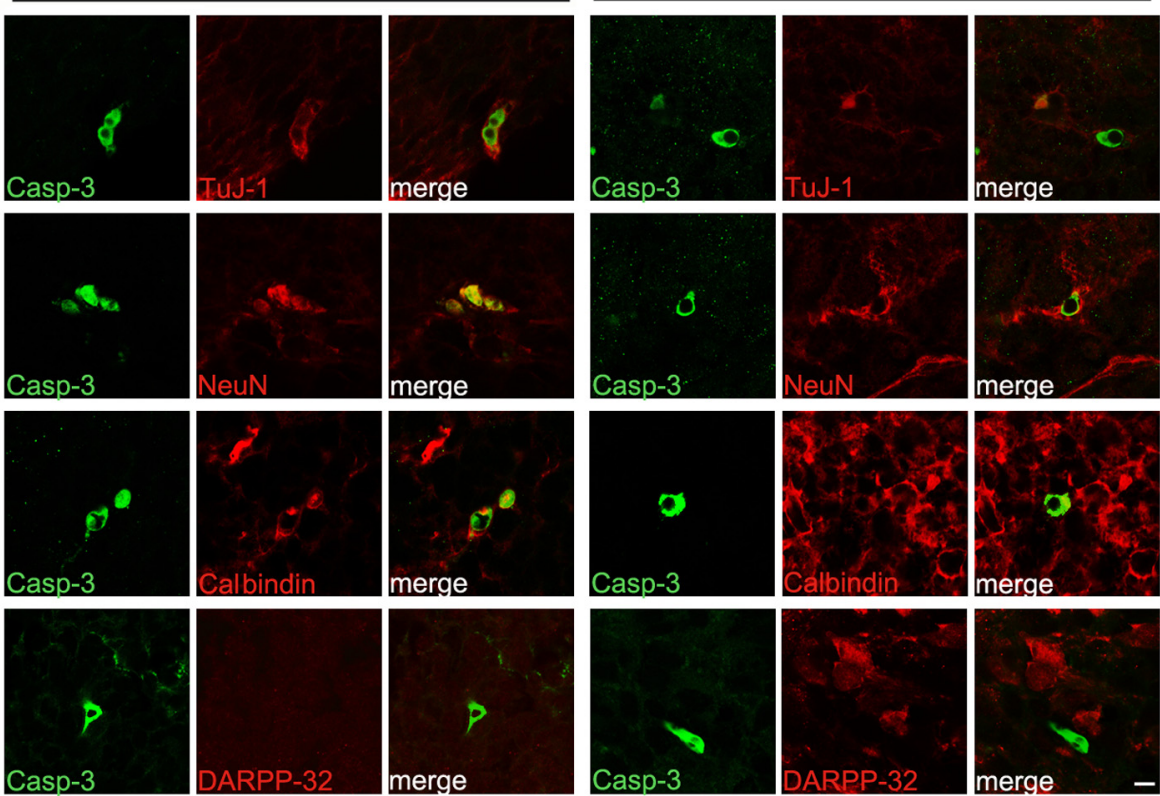

Figure 1. BDNF promotessurvival of immature MSN of the indirectpathway. $A, B D N F$ protein levels in the striatumatE16.5 and P21.B, Counts of striatal neurons in WT and $B d n f^{-/-}$miceatP10 $-P 14(n=$ 3 for each genotype). C, Counts of striatal DRD2-expressing cells in Drd2-EGFP and Drd2-EGFP;Bdnf ${ }^{-1-}$ mice at P10-P14 ( $n=3-4$ per genotype). D, Immunohistochemistry of activated caspase-3, counter-stained with Nissl. Scale bar, $25 \mu \mathrm{m}$. E, Density of cells containing activated caspase-3 in the striatum and the LGEVZ/SVZ of WT and Bdnf ${ }^{-l-}$ mice at PO $(n=3) . \boldsymbol{F}$, Colocalization of caspase-3-positive cells with specific neuronal markers in the LGE VZ/SVZ and the striatum of $B d n f^{-1-}$ mice at P0. Scale bar, $5 \mu$ m. Error bars indicate SEs. ${ }^{*} p<0.05 ;{ }^{* *} p<0.01 ;{ }^{* * *} p<0.001$.

this phenotype in mutant mice where deletion of the $B d n f$ gene was mediated by Wnt1-Cre (Danielian et al., 1998) in the developing midbrain and hindbrain (data not shown).

To determine which population of striatal neurons was affected by the $B d n f$ deletion in the midbrain, we crossed $B d n f^{T h}$ and control mice to bacterial artificial chromosome (BAC) transgenic mice expressing fluorescent proteins under the control of the promoter for either DRD1a (Drd1a-tdTomato) (Shuen et al., 2008) or DRD2 (Drd2-EGFP) (Day et al., 2006). By using these two fluorescent proteins as markers, we found that the number of 

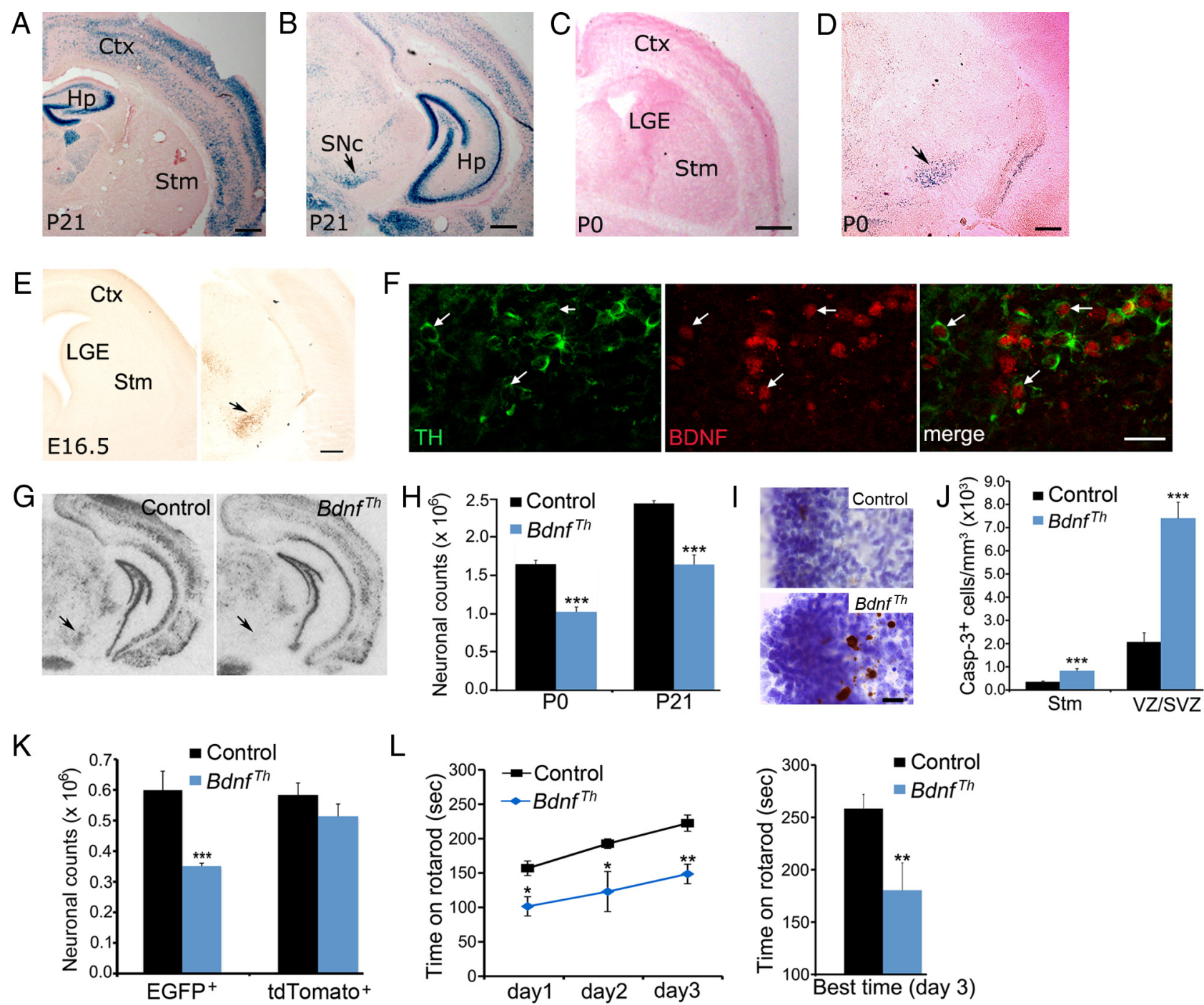

Figure 2. Midbrain dopaminergic neurons are the source of BDNF required for survival of MSNs of the indirect pathway. $A-D, B D N F$ expression in $B d n f$ acZ/+ brain at P0 and P21, as revealed with X-gal staining for $\beta$-galactosidase (blue). Scale bars: $\boldsymbol{A}-\boldsymbol{C}, 500 \mu \mathrm{m} ; \boldsymbol{D}, 250 \mu \mathrm{m}$. $\boldsymbol{E}$, BDNF expression in $B d n f^{d a c Z /+}$ embryos at E16.5, as revealed with immunohistochemistry of $\beta$-galactosidase. The arrow denotes the substantia nigra. Scale bar, $250 \mu \mathrm{m}$. $\boldsymbol{F}$, Colocalization of TH with $\beta$-galactosidase in the substantia nigra of $B d n f^{2 a c z /+}$ embryos at E16.5. Arrows denote representative neurons expressing both TH and BDNF. Scale bar, $25 \mu \mathrm{m}$. $\mathbf{G}$, Th-Cre-mediated deletion of the $B d n f$ gene. Arrows denote the substantia nigra. $\boldsymbol{H}$, Counts of Nissl-stained striatal neurons in control and $B d n f^{\text {th }}$ mice at P0 and P21 ( $n=3-5$ mice per group). I, Immunohistochemistry of activated caspase-3 in control and Bdnf ${ }^{\text {Th }}$ mice at P0. Scale bar, $25 \mu \mathrm{m}$. J, Density of cells containing activated caspase-3 in the striatum and the LGE of control and Bdnf ${ }^{\text {th }}$ mice at PO $(n=3-5)$. , Counts of EGFP-and tdTomato-expressing striatal neurons in control and Bdnf ${ }^{\text {h }}$ mice harboring either Drd2-EGFP or Drd $1 a-t d T$ Tomato at P21 ( $n=3-5$ mice per group). $L$, Control and $B d n f^{h}$ mice ( $n=11$ and 7 , respectively) at 6 months of age were tested on a rotarod. Data represent averages of scores from three trials each day for three consecutive days (left) and best score on the third day (right). Ctx, Cerebral cortex; Hp, hippocampus; SNc, substantia nigra pars compacta; Stm, striatum. Error bars indicate SEs. ${ }^{*} p<0.05$; ${ }^{* *} p<0.01$; ${ }^{* * *} p<0.001$.

MSNs in the indirect pathway (expressing EGFP) was reduced by $42 \%$ in $B d n f^{T h}$ mice, whereas the number of MSNs of the direct pathway (expressing tdTomato) was not significantly affected (Fig. $2 \mathrm{~K}$ ). These results indicate that BDNF produced by the dopaminergic neurons of the midbrain support survival of immature MSNs in the indirect pathway. $B d n f^{T h}$ mice performed poorly on rotarod tests at 6 month of age (Fig. $2 L$ ), which reinforces the importance of MSNs of the indirect pathway in motor coordination.

NT3-to-TrkC signaling promotes survival of immature MSNs of the direct pathway

Since the survival of MSNs of the direct pathway was not affected in $B d n f^{T h}$ mice, we investigated whether another neurotrophin might play a role in survival of this neuronal population. Using ELISA, we detected the NT3 protein in lysates prepared from the striatum dissected from mouse embryos at E16.5 and mice at P21
(Fig. 3A). TrkC mRNA was found throughout the adult striatum (Fig. 3B). To further document TrkC expression in striatal neurons, we cultured striatal neurons isolated from newborn mice and stained the cultures with antibodies to TrkC, NeuN, and DRD1a. We found that 79\% (76/96) of NeuN-expressing neurons and $86 \%(96 / 111)$ of DRD1a-expressing neurons were positive for TrkC (Fig. 3C,D). This expression data prompted us to hypothesize that NT3-to-TrkC signaling might be crucial for the survival of MSNs. Indeed, TrkC ${ }^{-1-}$-null mice showed 33\% reduction in the total striatal neuron number at $\mathrm{P} 0$, compared with WT mice (Fig. 3E).

We performed in situ hybridization to locate a brain region that may produce NT3 to support survival of developing MSNs. We found that in newborn mice Ntf3 mRNA for NT3 was not present in the striatum (Fig. $4 A$ ), but it was present in the substantia nigra (Fig. $4 B$ ). This observation prompted us to posit that NT3, like BDNF, is transported to the developing striatum from 
A

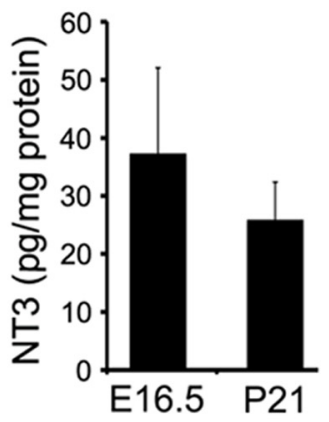

B

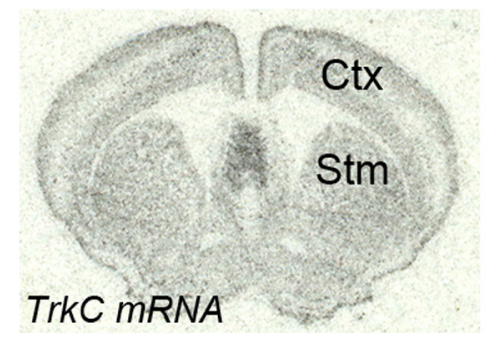

C
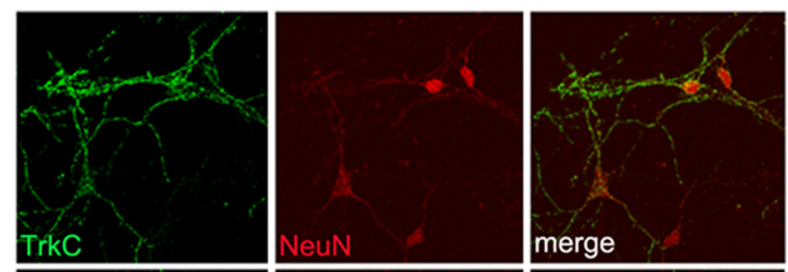

D
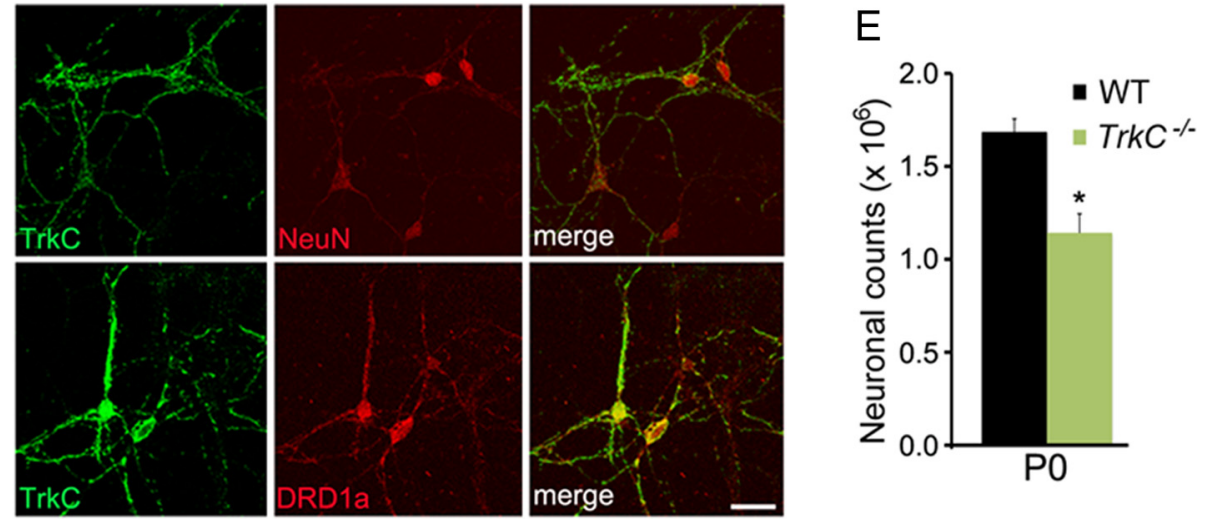

Figure 3. NT3-to-TrkC signaling is important for survival of striatal neurons. $\boldsymbol{A}$, NT3 protein levels in the striatum were measured at E16.5 and P21. $\boldsymbol{B}$, Radioactive in situ hybridization shows TrkC mRNA expression in the adult striatum (Stm) and cortex (Ctx). C, Many cultured striatal neurons, labeled by an antibody to neuronal marker (NeuN), express TrkC at $14 \mathrm{~d}$ in vitro. D, The majority of the MSNs of the direct pathway, labeled by an antibody to DRD1a, express TrkC. Scale bar, $25 \mu \mathrm{m}$. $\boldsymbol{E}$, Counts of striatal neurons from Nissl-stained sections in WT and TrkC ${ }^{-1-}$ mice at P0 ( $n=3$ ). Error bars indicate SEs. ${ }^{*} p<0.05$.

the dopaminergic neurons of the midbrain. To test this hypothesis, we crossed mice carrying a floxed $N t f 3$ allele to Th-Cre mice and obtained $N t f 3^{\text {lox/lox }}$ (control) and Th-Cre; $N t 3^{\text {lox/lox }}$ (mutant, termed $N t 3^{T h}$ ). In situ hybridization confirmed abolishment of NT3 expression in the substantia nigra of $N t 3^{T h}$ mice (Fig. $4 C, D$ ).

Stereological analysis showed that the number of striatal neurons was reduced by $30 \%$ and $22 \%$ in $N t 3^{T h}$ mice at P0 and P21, respectively, compared with age-matched control mice (Fig. 4E). $N t 3^{T h}$ mice also displayed increased apoptosis in the LGE VZ/ SVZ and the striatum at P0 (Fig. $4 F, G$ ). The majority of apoptotic cells expressed TuJ-1 (71\% in VZ/SVZ and 54\% in striatum), NeuN (71\% in VZ/SVZ and $81 \%$ in striatum), and calbindin (89\% in VZ/SVZ and 59\% in striatum), but not DARPP32 (0\% in both VZ/SVZ and striatum), indicating that most of them are immature MSNs. We then examined which population of MSNs was influenced by the Ntf3 deletion by introducing DrdlatdTomato and Drd2-EGFP transgenes to $N t 3^{\text {Th }}$ and control mice. Remarkably, the number of the MSNs of the direct pathway (tdTomato $^{+}$) was reduced by $35 \%$, whereas the number of the MSNs of the indirect pathway $\left(\mathrm{EGFP}^{+}\right)$was not significantly affected (Fig. 4H). This neuronal loss led to impaired motor coordination, as assessed in 6-month-old mice using rotarod tests (Fig. 4I). Therefore, NT3 derived from the midbrain dopaminergic neurons is a key trophic factor for the survival of developing MSNs of the direct pathway in the LGE and striatum.

\section{Discussion}

Our results clearly show that neurotrophic factors are crucial for survival of immature striatal neurons at their origin as well as at their final destination. Genetic studies have demonstrated that PNS neurons depend on neurotrophic factors for survival during embryogenesis and early postnatal life. For example, deletion of the gene for NGF leads to $>70 \%$ neuronal loss in dorsal root ganglia and $>95 \%$ neuronal loss in the superior cervical ganglia (Smeyne et al., 1994). However, the role of neurotrophic factors in the survival of developing brain neurons remains unclear. Most brain regions are very large in size compared with PNS ganglia, which makes detection of neuronal loss difficult. The stereological method is essential to assess neuronal loss in the brain; however, this method was not widely used at the time when mouse knock-outs of neurotrophic factors and their receptors were generated. This technical challenge may have hindered progress in evaluation of the role of neurotrophic factors in neuronal survival of the developing brain. Using stereological analysis, we previously observed that selective deletion of the TrkB gene in the progenitor cells of striatal neurons led to a large loss of MSNs of the indirect pathway (Baydyuk et al., 2011), suggesting that the TrkB ligands, BDNF and NT4/5, should play a key role in survival of this population of striatal neurons. In this study, we confirmed this prediction and identified BDNF produced in the midbrain dopaminergic neurons as the source of neurotrophic factors crucial for survival of developing MSNs of the indirect pathway. Furthermore, this study shows that the midbrain dopaminergic neurons also produce NT3 to promote survival of immature MSNs of the direct pathway. These results indicate that neurotrophic factors are key to the survival of at least some neuronal populations in the developing brain.

Our results indicate that neurotrophins promote neuronal survival in the PNS and the CNS at different locations and via distinct modes. No evidence indicates that immature PNS neurons depend on neurotrophins for survival at their origin. Once they reach their final position and form connections with their targets, many of them have to compete for a limiting amount of 

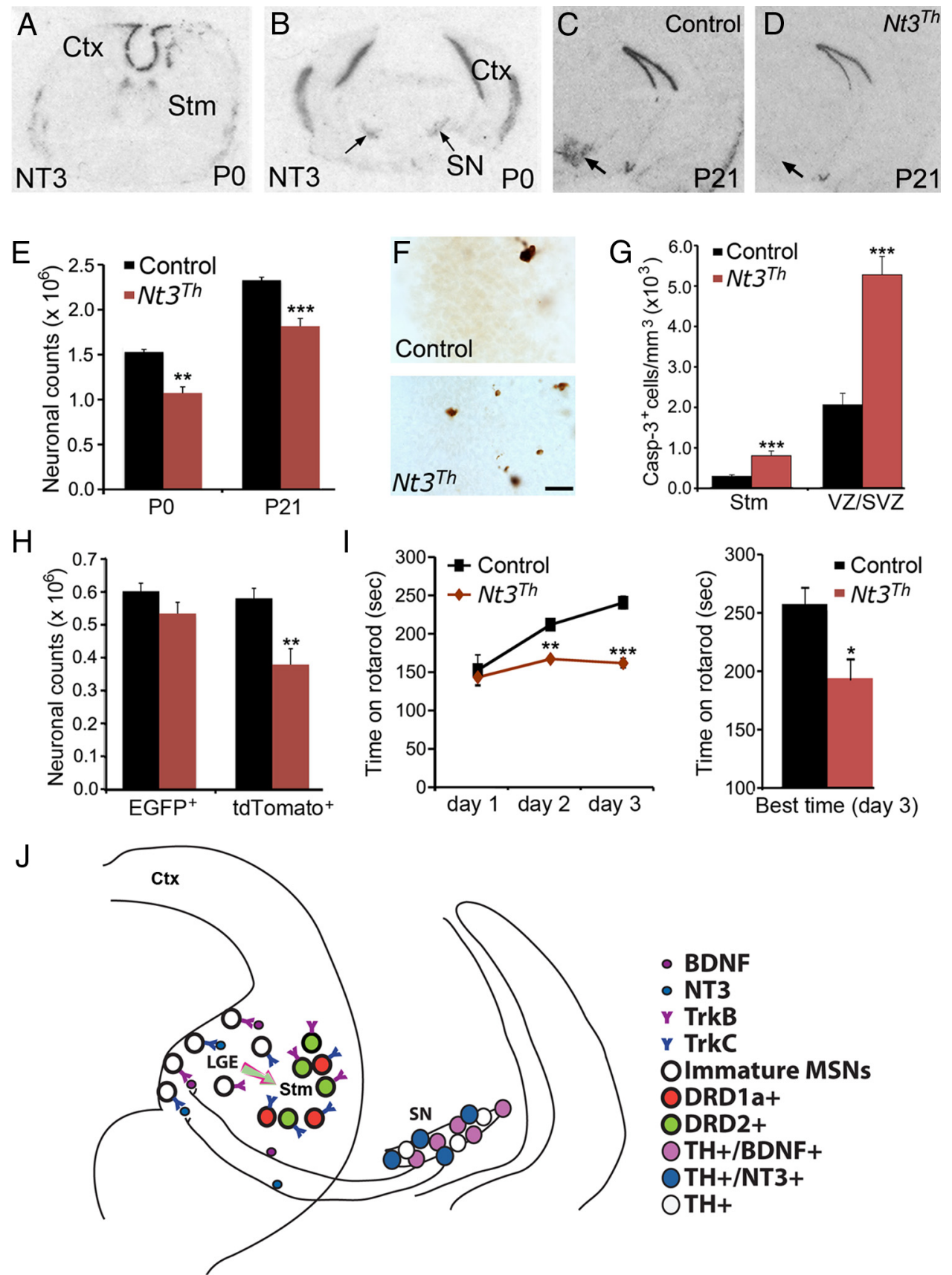

- BDNF

- NT3

Y TrkB

Y TrkC

Olmmature MSNs

ODRD1a+

ODRD2+

OTH+/BDNF+

TH+/NT3+

$\mathrm{OTH}+$

Figure 4. NT3 from midbrain dopaminergic neurons promotes survival of immature MSNs of the direct pathway. $\boldsymbol{A}, \boldsymbol{B}$, Distribution of Ntf3 mRNA in the WT brain at P0. Arrows denote the substantia nigra. $\boldsymbol{C}, \boldsymbol{D}$, In situ hybridization shows the absence of $N t f 3 \mathrm{mRNA}$ in the substantia nigra (arrows) of $N t 3^{T h}$ mice at P21. E, Counts of Nissl-stained striatal neurons in control and $N t 3^{T h}$ mice at P0 and P21 ( $n=3-5$ mice per group). $F$, Immunohistochemistry of activated caspase-3 revealed apoptotic cells in the LGE VZ/SVZ of control and Nt ${ }^{\text {Th }}$ mice at PO. Scale bar, $25 \mu \mathrm{m}$. G, Density of cells containing activated caspase-3 in the striatum and the LGE of control and Nt $3^{T h}$ mice at PO $(n=3-4)$. $\boldsymbol{H}$, Counts of EGFP- and tdTomato-expressing striatal cells in control and Nt ${ }^{T h}$ mice harboring either Drd2-EGFP or Drd1a-tdTomoato at P21 $(n=3-5) . I, N t 3^{T h}$ mice $(n=8)$ exhibited poor motor performance and impaired motor learning compared with control mice $(n=7)$, assessed by rotarod tests. $J$, A model showing that BDNF and NT3 anterogradely transported from mesencephalic dopaminergic neurons regulate survival of immature neurons in the indirect and direct pathways, respectively. Ctx, Cerebral cortex; Stm, striatum; SN, substantia nigra. Error bars indicate SEs. ${ }^{*} p<0.05 ;{ }^{* *} p<0.01 ;{ }^{* * *} p<0.001$.

target-derived neurotrophins for survival. These neurotrophin molecules are internalized at axonal terminals and retrogradely transported to cell bodies to activate pro-survival signaling cascades (Zweifel et al., 2005). In this way, target tissues determine the final size of the innervating neuronal population. However, in the striatum developing MSNs become dependent on neurotrophins for survival even before they reach their final position, as our results show that there are some apoptotic cells in the LGE in newborn WT mice and that deficiency of either BDNF or NT3 greatly increases apoptotic cell number in the LGE. Furthermore, our results indicate that the BDNF and NT3 proteins critical for survival of developing MSNs are produced in the midbrain dopaminergic neurons and anterogradely transported to the LGE and striatum. It is important to note that the loss of MSNs, particularly the neurons in the direct pathway, is not as striking as neuronal losses observed in the PNS of mice lacking neurotrophins or their receptors. This is likely due to the presence of additional survival factors for MSNs. 
In conclusion, our study provides genetic evidence that BDNF and NT3 produced in the midbrain dopaminergic neurons play a key role in the survival of immature striatal projection neurons of the indirect and direct pathways in the LGE and striatum (Fig. $4 J)$. This finding suggests that innervating neurons can regulate the size of their targeting neuronal population in the brain by regulating their survival through neurotrophins during embryogenesis and early postnatal development.

\section{References}

Alcántara S, Frisén J, del Río JA, Soriano E, Barbacid M, Silos-Santiago I (1997) TrkB signaling is required for postnatal survival of CNS neurons and protects hippocampal and motor neurons from axotomy-induced cell death. J Neurosci 17:3623-3633. Medline

Altar CA, Cai N, Bliven T, Juhasz M, Conner JM, Acheson AL, Lindsay RM, Wiegand SJ (1997) Anterograde transport of brain-derived neurotrophic factor and its role in the brain. Nature 389:856-860. CrossRef Medline

Baydyuk M, Russell T, Liao GY, Zang K, An JJ, Reichardt LF, Xu B (2011) TrkB receptor controls striatal formation by regulating the number of newborn striatal neurons. Proc Natl Acad Sci U S A 108:1669-1674. CrossRef Medline

Bolam JP, Hanley JJ, Booth PA, Bevan MD (2000) Synaptic organisation of the basal ganglia. J Anat 196:527-542. CrossRef Medline

Danielian PS, Muccino D, Rowitch DH, Michael SK, McMahon AP (1998) Modification of gene activity in mouse embryos in utero by a tamoxifeninducible form of Cre recombinase. Curr Biol 8:1323-1326. CrossRef Medline

Day M, Wang Z, Ding J, An X, Ingham CA, Shering AF, Wokosin D, Ilijic E, Sun Z, Sampson AR, Mugnaini E, Deutch AY, Sesack SR, Arbuthnott GW, Surmeier DJ (2006) Selective elimination of glutamatergic synapses on striatopallidal neurons in Parkinson disease models. Nat Neurosci 9:251-259. CrossRef Medline

Gorski JA, Zeiler SR, Tamowski S, Jones KR (2003) Brain-derived neurotrophic factor is required for the maintenance of cortical dendrites. J Neurosci 23:6856-6865. Medline

Hofer M, Pagliusi SR, Hohn A, Leibrock J, Barde YA (1990) Regional distribution of brain-derived neurotrophic factor mRNA in the adult mouse brain. EMBO J 9:2459-2464. Medline

Kawaguchi Y (1997) Neostriatal cell subtypes and their functional roles. Neurosci Res 27:1-8. CrossRef Medline

Kriegstein AR, Noctor SC (2004) Patterns of neuronal migration in the embryonic cortex. Trends Neurosci 27:392-399. CrossRef Medline

Lee FS, Chao MV (2001) Activation of Trk neurotrophin receptors in the absence of neurotrophins. Proc Natl Acad Sci U S A 98:3555-3560. CrossRef Medline

Lee MK, Tuttle JB, Rebhun LI, Cleveland DW, Frankfurter A (1990) The expression and posttranslational modification of a neuron-specific betatubulin isotype during chick embryogenesis. Cell Motil Cytoskeleton 17: 118-132. CrossRef Medline

Liebl DJ, Tessarollo L, Palko ME, Parada LF (1997) Absence of sensory neurons before target innervation in brain-derived neurotrophic factor-, neurotrophin 3-, and TrkC-deficient embryonic mice. J Neurosci 17:9113-9121. Medline

Lindeberg J, Usoskin D, Bengtsson H, Gustafsson A, Kylberg A, Söderstrom S, Ebendal T (2004) Transgenic expression of Cre recombinase from the tyrosine hydroxylase locus. Genesis 40:67-73. CrossRef Medline

Minichiello L, Klein R (1996) TrkB and TrkC neurotrophin receptors cooperate in promoting survival of hippocampal and cerebellar granule neurons. Genes Dev 10:2849-2858. CrossRef Medline

Oppenheim RW (1991) Cell death during development of the nervous system. Annu Rev Neurosci 14:453-501. CrossRef Medline

Rauskolb S, Zagrebelsky M, Dreznjak A, Deogracias R, Matsumoto T, Wiese S, Erne B, Sendtner M, Schaeren-Wiemers N, Korte M, Barde YA (2010) Global deprivation of brain-derived neurotrophic factor in the CNS reveals an area-specific requirement for dendritic growth. J Neurosci 30: 1739-1749. CrossRef Medline

Reichardt LF (2006) Neurotrophin-regulated signalling pathways. Philos Trans R Soc Lond B Biol Sci 361:1545-1564. CrossRef Medline

Shuen JA, Chen M, Gloss B, Calakos N (2008) Drdla-tdTomato BAC transgenic mice for simultaneous visualization of medium spiny neurons in the direct and indirect pathways of the basal ganglia. J Neurosci 28:2681-2685. CrossRef Medline

Smeyne RJ, Klein R, Schnapp A, Long LK, Bryant S, Lewin A, Lira SA, Barbacid M (1994) Severe sensory and sympathetic neuropathies in mice carrying a disrupted Trk/NGF receptor gene. Nature 368:246-249. CrossRef Medline

Voorn P, Kalsbeek A, Jorritsma-Byham B, Groenewegen HJ (1988) The prenatal and postnatal development of the dopaminergic cell groups in the ventral mesencephalon and the dopaminergic innervation of the striatum of the rat. Neuroscience 25:857-887. CrossRef Medline

Xie Y, Hayden MR, Xu B (2010) BDNF overexpression in the forebrain rescues Huntington's disease phenotypes in YAC128 mice. J Neurosci 30:14708-14718. CrossRef Medline

Xu B, Goulding EH, Zang K, Cepoi D, Cone RD, Jones KR, Tecott LH, Reichardt LF (2003) Brain-derived neurotrophic factor regulates energy balance downstream of melanocortin-4 receptor. Nat Neurosci 6:736-742. CrossRef Medline

Zweifel LS, Kuruvilla R, Ginty DD (2005) Functions and mechanisms of retrograde neurotrophin signalling. Nat Rev Neurosci 6:615-625. CrossRef Medline 